\title{
Cerebrovascular Disease in COVID-19: Is There a Higher Risk of Stroke?
}

Marcos Altable, Juan Moisés de la Serna

Funding: The author(s) received no specific funding for this work.

Potential competing interests: The author(s) declared that no potential competing interests exist.

\begin{abstract}
The presence of stroke is being observed in young adults (under 50 years of age) without cardiovascular risk factors suffering from COVID-19. It is speculated whether there is really a significant increase, as few cases have yet been described, or whether the infection actually favors their development. Cerebrovascular events were more common in older patients with stroke risk factors such as hypertension and diabetes mellitus, and those who had elevated fibrin D-dimers. Multiple cases reports and series about cerebrovascular disease in COVID-19 has been informed. The mechanism that causes cerebral ischemia in COVID-19 remains undiscovered, however, progressively there is increasing evidence of a hypercoagulable state that could be or contribute to the cause of cerebrovascular disease. We review the current literature about cerebrovascular disease, both epidemiology and etiology. More studies are needed to understand COVID-19 neuropathogenesis and the presence of stroke in this patient.
\end{abstract}

The presence of stroke is currently being observed in young (under 50 years of age) without cardiovascular risk factors. Oxley and colleagues recently described a case series of large-vessel strokes as an initial presentation in COVID-19 patients younger than 50 years old (1), that is, people without age or risk factors sufficient to expect a stroke. A retrospective study of data from the Covid-19 outbreak in Wuhan, China, showed that the incidence of stroke among hospitalized COVID-19 patients was approximately 5\%, with the youngest patient being 55 years old (2). There is speculation whether there is really a significant increase, as only few cases have been described, or whether the infection actually favors the development of stroke. Cerebrovascular events were more common in older patients with stroke risk factors such as hypertension and diabetes mellitus, and those who had elevated fibrin D-dimers (3) (4). Researchers at the University Hospital of Zurich noted that the SARS-CoV-2 virus or COVID-19 infects hosts through the angiotensin-converting enzyme (ACE2), expressed 
not only in the lungs but also in the heart, kidney, intestine and endothelial cells. And they described three cases in which they observed direct viral infection of the cells and diffuse endothelial inflammation (endothelitis) (5). COVID-19 endothelitis could explain the impaired microcirculatory function in different vascular beds and its clinical sequelae in patients with COVID-19 $(4,5)$.

Another study of 184 intensive care unit (ICU) patients with proven COVID-19 pneumonia found that $31 \%$ of them have symptomatic acute pulmonary embolism, deep vein thrombosis, ischemic stroke, myocardial infarction, or systemic arterial embolism. Researchers speculated a problem with the coagulation system or the endothelial lining of blood vessels (6). Coagulopathy and vascular endothelial dysfunction have been proposed as complications of COVID-19 (7).

Li, Y., et al.'s retrospective study 221 patients with COVID-19, 13 (5.9\%) developed cerebrovascular disease after infection. Of these patients, 11 (84.6\%) were diagnosed with ischemic stroke, 1 (7.7\%) with cerebral venous sinus thrombosis, and $1(7.7 \%)$ with cerebral hemorrhage. With the exception of a 32-year-old patient with cerebral venous sinus thrombosis, the patient's age ranged from 57 to 91 (4). All patients showed an increased inflammatory response and a state of hypercoagulability (4). These findings suggest that older adults affected by COVID-19 may be more likely to develop cerebrovascular disease (CVD) and that more attention should be given to those with risk factors for vascular disease. In the study of Yaghy et al., out of 3556 hospitalized patients diagnosed with COVID-19 infection, 32 patients (0.9\%) had imaging proven ischemic stroke (8). It should be noted that all study participants are hospitalized patients with symptoms. Notably, only about $20 \%$ of those infected have symptoms $(9,10)$; therefore, if around $1 \%$ of patients presented stroke, this corresponds to $0.2 \%$ of all those infected. In the considerably smaller sample of LiY, et al. that had 221 cases, data indicated $5 \%$ of ischemic strokes (5.9\% of strokes) in symptomatic COVID-19 patients, upon admission, which corresponds to $1 \%$ of the total number of infected cases (4). We can consequently conclude with current data that between 0.2 to $1 \%$ of those infected with COVID-19 develop ischemic strokes. Eleven of 13 (84.6\%) CVD patients had severe COVID-19 infection, suggesting that severe infection may be an indicator of CVD, especially of acute ischemic stroke.

The authors conclusively consider that CVD is not uncommon in patients with COVID-19. , that the patients who presented CVD were mostly older adults, and that the latter had multiple risk factors (e.g., hypertension and diabetes), more severe COVID-19 infection, and an inflammatory response that induced the state of hypercoagulable blood (4). SARS-CoV-2 penetrates the cell using as receptor the angiotensin-converting enzyme 2 (ACE2), a membrane exopeptidase mainly presents in the airway epithelium, pulmonary 
parenchyma, vascular endothelium, brain, kidney, heart, testicular tissue and intestine (11). The role of ACE2 is the transformation of angiotensin I into angiotensin II. These final products have vasodilatory, antifibrotic, and anti-inflammatory effects and favors natriuresis. ACE2 has been identified as the functional receptor for COVID-19 (12-15). Autopsy results of patients with COVID-19 showed that brain tissue was hyperemic and edematous, and some degenerate neurons (3). And recent autopsy findings suggest thrombotic microangiopathy in multiple organs, especially in the lungs. With this evidence, the most plausible mechanism of early cerebrovascular accidents could be hypercoagulability leading to macro and micro thrombi formation in the vessels (16). Severe cases of COVID-19 have been shown high levels of angiotensin II, and these levels has been correlated with SARS-CoV-2 viral load and lung damage (17). This same effect has been observed during the SARS outbreak in $2003(18,19)$. Moreover, large-vessel stroke was reported during the 2004 SARS-CoV-1 outbreak in Singapore (20). Inflammation has been increasingly recognized as a key contributor to the pathophysiology of CVD and is involved in acute intravascular events caused by disruption of the blood supply (21). Meanwhile, inflammatory factors in the blood (for example, interleukin and C-reactive protein) are responsible for the first molecular events triggered by coagulation abnormalities (22-24).

In the study of Mao et.al, 5.7\% of patients developed CVD later in the course of illness in patients with severe infection (3). In Li Y et al.'s study, the incidence of stroke in COVID-19 patients was about $5 \%$, with a median age of 71.6 years (4). These patients had severe disease and a higher incidence of risk factors, such as hypertension, diabetes, coronary artery disease, and previous cerebrovascular disease (4). Average time of onset of stroke after COVID-19 diagnosis was 12 days (4). Elevated CRP and D-dimer indicating high inflammatory state and abnormalities with coagulation cascade might respectively contribute to strokes in patients with COVID-19 infection (4). In a study of 191 COVID-19 patients in Wuhan, China, researchers found that D-dimer levels of $>1 \mu \mathrm{g} / \mathrm{L}$ were associated with an 18-fold increase in the likelihood of death before discharge (7). Patients with COVID-19 with an elevated serum ferritin level had a 9-fold increase in the likelihood of death before discharge (7). Hyperferritinemia, although nonspecific, can be a marker of an inflammatory response $(25,26)$. Macrophage activation syndrome (MAS), also called cytokines storm is a rare complication of Kawasaki disease (KD). Hyperferritinemia is highly specific and sensitive for detecting MAS (27). Notably, a list of KD cases in children with COVID-19 has recently been reported (28). The elevation of ferritine levels has also be reported in patients with antiphospholipid syndrome and catastrophic antiphospholipid syndrome, which are both associated with arterial and venous thromboses (29). Recently antiphospholipid 
syndrome has been involved in the coagulopathy in patients with COVID-19 with cerebral ischemia (30).

The mechanism causing cerebral ischemia in patients with COVID-19 it remains undiscovered, however, there is increased evidence for a hypercoagulability (31). A recent study from the Netherlands by Klock et al. demonstrated that $31 \%$ of critically ill intensive care unit (ICU) patients develop thrombotic complications (32). Another study exploring activated partial thromboplastin time-based clot waveform analysis (CWA) in COVID-19 patients concluded that CWA parameters demonstrate hypercoagulability that precedes or coincides with severe illness (16). At the present, multiple reports of pulmonary embolism are available in the literature and it has been observed bacterial and viral infections (33). Autopsy and pathology findings are scarcely available, but recent autopsy findings have showed thrombotic microangiopathy in multiple organs, especially in the lungs (16) (21) (23) (30). On the other hand, pathophysiology could be causally related to the infection or hypoxia. Neuroinflammation together with prolonged hypoxia may promote neurological manifestations (34).

In stroke associated with COVID-19, both presentation and outcome are often worse compared to other strokes. It has been reported that stroke developed mostly in patients with severe pneumonia and multiorg an failure and the outcome was poor (6). In addition to the mechanisms directly mediated by COVID-19, another factor at play is the delay in the presentation in the emergency services of strokes (35), since people are afraid of interacting with the health system due to the risk of being infected. . The timely and effective delivery of acute stroke care, especially reperfusion therapy for ischemic stroke, significantly improves stroke outcomes $(2,20)$.

\section{Conclusions}

It is still unclear whether there is an increased risk of stroke in COVID-19 patients, whether this condition is caused by the virus, or whether the incidence of stroke in young COVID-19 patients is increased. The pathophysiology of stroke in this disease appears to be due to a state of hypercoagulability. The maintained hypoxia could contribute to an increased severity of CVD. Further studies are needed for understanding neuropathogenesis of COVID-19 and the presence of stroke. It is accurately to perform high-quality and rigorous studies that are well controlled, since making forceful statements based on small case series from a few centers with no comparison groups could be controversial. Case series are useful in raising suspicion of a novel or unique association or risk factor but should be validated in methodologically sound studies. References

1. Gunasekaran K, Amoah K, Rajasurya V, Buscher MG. Stroke in a young COVID -19 patient. QJM An Int J Med [Internet]. 2020; Available from: 
https://doi.org/10.1093/qjmed/hcaa177

2. Oxley TJ, Mocco J, Majidi S, Kellner CP, Shoirah H, Singh IP, et al. Large-Vessel Stroke as a Presenting Feature of Covid-19 in the Young. N EnglJ Med [Internet]. 2020 May 14 [cited 2020 May 22];382(20):e60. Available from: http://www.nejm.org/doi/10.1056/NEJMc2009787

3. Mao L, Jin H, Wang M, Hu Y, Chen S, He Q, et al. Neurologic Manifestations of Hospitalized Patients with Coronavirus Disease 2019 in Wuhan, China. JAMA Neurol. 2020;

4. Li Y, Wang M, Zhou Y, et al. Acute cerebrovascular disease following COVID-19: A single center, retrospective, observational study. Lancet 2020; Epub 2020 Mar 13. Available from: http://dx.doi.org/10.2139/ssrn.3550025

5. Varga Z, Flammer AJ, Steiger P, Haberecker M, Andermatt R, Zinkernagel AS, et al. Endothelial cell infection and endotheliitis in COVID-19. Vol. 395, The Lancet. Lancet Publishing Group; 2020. p. 1417-8.

6. Morassi M, Bagatto D, Cobelli M, D’Agostini S, Gigli GL, Bnà C, et al. Stroke in patients with SARS-CoV-2 infection: case series. J Neurol [Internet]. 2020 May 20 [cited 2020 May 23];1-8. Available from: http://link.springer.com/10.1007/s00415-020-09885-2

7. Zhou F, Yu T, Du R, Fan G, Liu Y, Liu Z, et al. Clinical course and risk factors for mortality of adult inpatients with COVID-19 in Wuhan, China: a retrospective cohort study. Lancet. 2020 Mar 28;395(10229):1054-62.

8. Yaghi S, Ishida K, Torres J, Mac Grory B, Raz E, Humbert K, et al. SARS2-CoV-2 and Stroke in a New York Healthcare System. Stroke [Internet]. 2020 May 20 [cited 2020 May 23];ST ROKEAHA120030335. Available from: http://www.ncbi.nlm.nih.gov/pubmed/32432996

9. Wang Y, T ong J, Qin Y, Xie T, Li J, Li J, et al. Characterization of an asymptomatic cohort of SARS-COV-2 infected individuals outside of Wuhan, China. Clin Infect Dis [Internet]. 2020; Available from: https://doi.org/10.1093/cid/ciaa629

10. Zhou R, Li F, Chen F, Liu H, Zheng J, Lei C, et al. Viral dynamics in asymptomatic patients with COVID-19. Int J Infect Dis [Internet]. 2020 Jul 1 [cited 2020 May 23];96:28890. Available from: https://linkinghub.elsevier.com/retrieve/pii/S1201971220303374 11. Baig AM, Khaleeq A, Ali U, Syeda H. Evidence of the COVID-19 Virus Targeting the CNS: T issue Distribution, Host-Virus Interaction, and Proposed Neurotropic Mechanisms. ACS Chemical Neuroscience. American Chemical Society; 2020.

12. Garabelli PJ, Modrall JG, Penninger JM, Ferrario CM, Chappell MC. Distinct roles for angiotensin-converting enzyme 2 and carboxypeptidase $A$ in the processing of angiotensins within the murine heart. Exp Physiol. 2008;93(5):613-21.

13. Stewart JA, Lazartigues E, Lucchesi PA. The ang iotensin converting enzyme 2/Ang- 
(1-7) axis in the heart: A role for mas communication? Vol. 103, Circulation Research. Circ Res; 2008. p. 1197-9.

14. Kassiri Z, Zhong J, Guo D, Basu R, Wang X, Liu PP, et al. Loss of angiotensinconverting enzyme 2 accelerates maladaptive left ventricular remodeling in response to myocardial infarction. Circ Hear Fail. 2009 Sep;2(5):446-55.

15. Imai Y, Kuba K, Rao S, Huan Y, Guo F, Guan B, et al. Angiotensin-converting enzyme 2 protects from severe acute lung failure. Nature. 2005 Jul 7;436(7047):112-6.

16. Avula A, Nalleballe K, Narula N, Sapozhnikov S, Dandu V, Toom S, et al. COVID-19 presenting as stroke. Brain Behav Immun [Internet]. 2020 [cited 2020 May 23];(April):01. Available from: https://doi.org/10.1016/j.bbi.2020.04.077

17. Liu Y, Yang Y, Zhang C, Huang F, Wang F, Yuan J, et al. Clinical and biochemical indexes from 2019-nCoV infected patients linked to viral loads and lung injury. Sci China Life Sci. 2020 Mar 1;63(3):364-74.

18. Li W, Moore MJ, Vasllieva N, Sui J, Wong SK, Berne MA, et al. Angiotensin-converting enzyme 2 is a functional receptor for the SARS coronavirus. Nature. 2003 Nov 27;426(6965):450-4.

19. Kuba K, Imai Y, Rao S, Gao H, Guo F, Guan B, et al. A crucial role of angiotensin converting enzyme 2 (ACE2) in SARS coronavirus-induced lung injury. Nat Med. 2005 Aug 10;11(8):875-9.

20. Umapathi T, Kor AC, Venketasubramanian N, Lim CCT, Pang BC, Yeo TT, et al. Large artery ischaemic stroke in severe acute respiratory syndrome (SARS). J Neurol. 2004 Oct;251(10):1227-31.

21. Iadecola C, Anrather J. The immunology of stroke: From mechanisms to translation. Vol. 17, Nature Medicine. Nat Med; 2011. p. 796-808.

22. Ding P, Zhang S, Yu M, Feng Y, Long Q, Yang H, et al. IL-17A promotes the formation of deep vein thrombosis in a mouse model. Int Immunopharmacol. 2018 Apr $1 ; 57: 132-8$.

23. Ji Y, Fish PM, Strawn TL, Lohman AW, Wu J, Szalai AJ, et al. C-reactive protein induces expression of tissue factor and plasminogen activator inhibitor-1 and promotes fibrin accumulation in vein grafts. J Thromb Haemost. 2014 Oct 1;12(10):1667-77.

24. Horvei LD, Grimnes G, Hindberg K, Mathiesen EB, Njølstad I, Wilsgaard T, et al. Creactive protein, obesity, and the risk of arterial and venous thrombosis. J Thromb Haemost. 2016 Aug 1;14(8):1561-71.

25. Rosário C, Zandman-Goddard G, Meyron-Holtz EG, D'Cruz DP, Shoenfeld Y. The Hyperferritinemic Syndrome: Macrophage activation syndrome, Still's disease, septic shock and catastrophic antiphospholipid syndrome. BMC Med [Internet]. 2013 Aug 22 [cited 2020 May 23];11(1):185. Available from: 
http://bmcmedicine.biomedcentral.com/articles/10.1186/1741-7015-11-185

26. Kell DB, Pretorius E. Serum ferritin is an important inflammatory disease marker, as it is mainly a leakage product from damaged cells. Vol. 6, Metallomics. Royal Society of Chemistry; 2014. p. 748-73.

27. Han SB, Lee S-Y. Macrophage activation syndrome in children with Kawasaki disease: diagnostic and therapeutic approaches. World J Pediatr [Internet]. 2020 May 16 [cited 2020 May 23]; Available from: http://link.springer.com/10.1007/s12519-02000360-6

28. Licciardi F, Pruccoli G, Denina M, Parodi E, Taglietto M, Rosati S, et al. SARS-CoV-2Induced Kawasaki-Like Hyperinflammatory Syndrome: A Novel COVID Phenotype in Children. Pediatrics [Internet]. 2020 May 21 [cited 2020 May 23];e20201711. Available from: http://pediatrics.aappublications.org/lookup/doi/10.1542/peds.2020-1711

29. Nayer A, Ortega LM. Catastrophic antiphospholipid syndrome: A clinical review. Vol. 3, Journal of Nephropathology. Society of Diabetic Nephropathy Prevention; 2014. p. 917.

30. Zhang Y, Xiao M, Zhang S, Xia P, Cao W, Jiang W, et al. Coagulopathy and Antiphospholipid Antibodies in Patients with Covid-19. N Eng I J Med. 2020 Apr 23;382(17):e38.

31. Thachil J, Tang N, Gando S, Falanga A, Cattaneo M, Levi M, et al. ISTH interim guidance on recognition and management of coagulopathy in COVID-19. JT hromb Haemost. 2020 Mar 25;18(5).

32. Klok FA, Kruip MJHA, van der Meer NJM, Arbous MS, Gommers DAMPJ, Kant KM, et al. Incidence of thrombotic complications in critically ill ICU patients with COVID-19. Thromb Res. 2020;

33. Grau AJ, Buggle F, Becher H, Zimmermann E, Spiel M, Fent T, et al. Recent bacterial and viral infection is a risk factor for cerebrovascular ischemia. Clinical and biochemical studies. Neurology. 1998;50(1):196-203.

34. Steardo L, Steardo L, Zorec R, Verkhratsky A. Neuroinfection may potentially contribute to pathophysiology and clinical manifestations of COVID-19. Acta physiologica (Oxford, England). NLM (Medline); 2020. p. e13473.

35. Teo K-C, Leung WCY, Wong Y-K, Liu RKC, Chan AHY, Choi OMY, et al. Delays in Stroke Onset to Hospital Arrival T ime During COVID-19. Stroke [Internet]. 2020 May 20 [cited 2020 May 23];ST ROKEAHA120030105. Available from: http://www.ncbi.nlm.nih.gov/pubmed/32432998 